\title{
Arhanan Yazıtı Üzerine Notlar
}

\author{
Zeynep Ülkü SINANOĞLU*
}

\section{Öz}

Moğolistan Türk dili, kültürü ve tarihi açısından son derece önemli bir coğrafyadır. Türk dilinin en eski yazılı kaynakları bu topraklarda bulunmuştur. Arhanan Yazıtı da Moğolistan'ın Bulgan eyaletinde (aymag) bulunmuş bir yazıttır. Yazıt diklemesine bir kayaya yazılmıştır ve 3 satır runik yazı ihtiva eder. Runik metin üzerine ilk okuma ve anlamlandırma çalışması ise 1965 yılında E. Tryjarski tarafından yapılmıştır. Arhanan Yazıtının hangi tarihte yazıldığı kesin olarak bilinmemektedir. Ancak söz varlığı ve bazı yazım özellikleri Uygur dönemi yazıtlarından olabileceğine işaret eder. Bu çalışmada Arhanan Yazıtı hakkında genel bilgilere yer verildikten sonra yazıttaki her bir satır tek tek ele alınıp runik metin dizgisi ve transliterasyonu verilecektir. Ardından önceki araştırmacıların okuyuşları ve tarafımızca hazırlanan okuma anlamlandırma denemesi yer alacaktır. Her bir satırın sonunda ilgili satıra dair ele alınan bazı sözcüklere ve yazım özelliklerine değinilecektir. Makalenin amacı bu zamana kadar yapılan çalışmalara toplu bir bakış sağlamak, birtakım sözcükler ve yazım özelliklerine dair açıklamalar getirmektir.

Anahtar Kelimeler: Arhanan Yazıtı, kaya yazıtları, Moğolistan’daki eski Türk yazıtları.

\footnotetext{
* Doktora Öğrencisi, İstanbul Üniversitesi, Edebiyat Fakültesi, Türk Dili ve Edebiyatı Bölümü, İstanbul, Türkiye. Elmek: zeynepsinanoglu27@gmail.com https://orcid.org/0000-0001-6538-0612.
} 


\title{
Notes on the Arkhanan Inscription
}

\begin{abstract}
Mongolia is an extremely important geography in terms of Turkic language, culture and history. The oldest written sources of the Tukic language were found here. The Arkhanan Inscription is also an inscription found in the Bulgan Aymag of Mongolia. The inscription was written upright on a rock and consists of 3 lines of runic text. First reading and interpretation study on the text has been done by Edward Tryjarski in 1965. It is not known yet for sure the period of the inscription. However, its vocabulary and some spelling features indicate that it may be from the Uyghur period inscriptions. In this study, after giving general information about the Arhanan Inscription, each line in the inscription will be handled one by one and the runic text string and transliteration will be given. After that, each line in the inscription is handled one by one and the runic text string, the readings of previous researchers and the reading prepared by us is given. At the end of each line, some words and spelling features that we have discussed about the relevant line will be mentioned. The aim of the study is to provide an overview of the works done so far and to provide explanations about some words and spelling features.
\end{abstract}

Keywords: Arkhanan Inscription, rock inscriptions, old Turkic inscriptions in Mongolia. 


\section{Extented Summary}

Mongolia is an extremely important geography in terms of Turkic language, culture and history. The oldest written sources of the Turkic language were found here. The first research trips to the region were the expeditions made by Finnish and Russian delegations in 1889-90. Atlases of the inscriptions found as a result of these researches began to be published. Following these, W. Radloff and V. Thomsen competed with each other for the analysis of Köktürk Alphabet. V. Thomsen announced to the scientific world in 1893 that the language of the inscriptions is Turkic. With the analysis of the alphabet, many texts were published, especially by W. Radloff and V. Thomsen. However, the majority of these studies are on inscriptions such as Kül Tègin, Bilge Kağan, Tunyukuk, Kara Balgasun, Ongi, which are large and voluminous inscriptions. Apart from these inscriptions, many short inscriptions have been found in Mongolia. These are a few lines of inscriptions, sometimes written on rocks and sometimes on various objects.

In this article, one of these short inscriptions, the Arhanan Inscription, will be discussed.The Arhanan Inscription was found in the Bulgan Aymag (province) of Mongolia. The inscription contains 3 lines of runic writing written on a rock wall. It is not known exactly when the inscription was written. Its vocabulary and some spelling features indicate that it may be from the Uyghur period inscriptions. The first reading comprehension study on the runic text was made in 1965 by E. Tryjarski. Tryjarski's work is based on retouched photographs taken by Gombojav, the photographer of the National Central Museum of Mongolia, in 1962. (Tryjarski, 1965: 423424). According to the information given by the Mongolian scientist Tsend Battulga, O. Namnandorj produced a hand-copy photograph of the inscription in 1966 (2005: 115). The runic text of the inscription was published by Rintchen (1968: 37). Later, S. Karjaubay (1980: 90-93), Klyaştornıy-Tryjarski (1990: 65-68), F. S. Baruţu Özönder (2000: 126-131), Ts. Battulga (2005: 115-121, 2020: 142), N. Bazilhan (2005: 128 ), İ. V. Kormusin-Ts. Battulga (2013: 204-219) and by E. Aydın (2018: 90-91) are studied.

In the inscription, it can be said that there is a blessed news or it is told. Line 1 is the longest line of the inscription. It was hoped that "Yay1 Kul Tarkan", who was the soldier of the city, "Tura Erkin, the nephew of the Holy Princess", brought a bri- 
degroom, and that he would be as solid as a rock with these two. 'I wrote the inscription, congratulations' on line 2 . The third line states that the inscription was written by the servant, that he was blessed and that he carved the inscription on the rock himself.

When we look at the vocabulary of the inscription, we come across proper names and titles. Such as Kul Tarkan, Tura Erkin.

The article consists of two parts: introduction and conclusion. The introduction contains general information about the inscription. After the introduction, each line in the inscription is handled one by one and the runic text string, the readings of previous researchers reading are given. After the transcription and translation of previous publications are given, reading-translation prepared by us is given. The lines are shown as (1), (2), (3). Unity is achieved in transcription. At the end of each line, some words and spelling features that we have discussed about the relevant line are mentioned. In the conclusion part, there is a holistic reading and translation of the inscription.

The aim of the study is to provide an overview of the works done so far and to provide explanations about some words and spelling features. 


\section{Giriş}

Arhanan yazıtı Moğolistan'ın Bulgan eyaleti (aymag), Hişig-Öndör kasabasında (sum) bulunmuştur. Üç satırlık runik metin ve damgalar bir kaya yüzüne kazınmıştır. Yazııın ilk okuma ve anlamlandırma denemesi 1965 yılında Edward Tryjarski tarafından yapılmıştır. Moğol bilim adamı Tsend Battulga'nın verdiği bilgiye göre O. Namnandorj 1966 yılında yazıtın elle kopyasını çıkarmıştır (2005: 115). Yazııın runik metin basımını Rinçen yapmıştır (1968: 37). Daha sonra S. Karjaubay (1980), Klyaştornı-Tryjarski (1990) F. S. Barutçu Özönder (2000), Ts. Battulga (2005), N. Bazılhan (2005), 2011 yılında yapılan Rus-Moğol keşif gezisi sonucu İ. V. KormuşinTs. Battulga (2013), E. Aydın (2018) ve son çalışma yazıtı birçok kez ziyaret eden Ts. Battulga (2020) tarafından yapılmıştır.

Arhanan Yazıtının hangi döneme ait olduğu kesin olarak bilinmemektedir. Ancak üzerinde bulunan damgalar ve söz varllğı Uygur dönemine ait olabileceğine işaret eder. Klyaştornıy-Tryjarski genel olarak 8. yüzyılın ikinci yarısı ya da 9. yüzyıl başı olarak tarihlendirirken (1990: 66), İ. Kormuşin- Ts. Battulga ise yaklaşık olarak 9. yüzyıl ortası olabileceğini söyler (2013: 218).

Yazıtta kutlu olan bir haber ya da olayın anlatıldığı söylenebilir. 1. satır, en uzun satırdır. Kutsal Prenses'in yeğeni Tura Erkin'in şehrin askeri olduğu, Yạı Kül Tarkan'ın (?) güvey getirdiği (?) bu ikisinin kaya gibi sağlam olması temenni edilmiştir. 2. satırda 'Yazıtı yazdım, kutlu olun' şeklindedir. 3. satırda ise, yazıtı yazanın hizmetkâr olduğu belirtildikten sonra tekrar kutlu olması temenni edilir ve kayaya yazıyı kendisinin kazıdığını bildirir.

Yazıt üzerine yapılan okumalar birbirlerinden harf tespiti ve okuyuş bakımından oldukça farklıdır. Bunun sebebi bu çalışmalarda kullanılan fotoğraf ve el kopyalarını okuma ve yorumlamadaki zorluktur. Tryjarski'nin çalışması 1962 yılında Moğolistan Ulusal Merkez Müzesinin fotoğrafçısı olan Gombojav'ın çektiği rötuşlu fotoğraflara dayanır (Tryjarski 1965: 423-424). Karjaubay'ın runik metni kendi el kopyasıdır. Klyaştornıy-Tryjarski ise çalışmalarında kulladıkları foroğrafların yeterli olmadığını büyük oranda Klyaştornıy'ın el kopyalarından faydalandıklarını belirtmişlerdir (1990: 65). Özönder'in çalışması kendisinden önceki araştırmacıların metinlerine dayanmaktadır (2000: 128). Son yıllarda yazıtı yerinde inceleyen Moğol araştırmacı Ts. Battulga'nın (2005: 115-121; 2020: 142-143) çalışmaları ve Kormuşin-Battulga 
(2013: 204-219) çalışmasında daha net fotoğraflar ortaya konmuştur.

Bu çalışma, mevcut çalışmaların görselleri ve runik metinleri karşılaştırılarak oluşturulmuştur. Önceki yayınların transkripsiyon ve çevirisi verildikten sonra, tarafımızca hazırlanan okuma-çeviri denemesi verilmiştir. Satırlar (1), (2), (3) şeklinde gösterilip, açıklamalar kısmında sözcükler ve bazı yazım özelliklerine değinilmiştir. Transkripsiyonda birlik sağlanmıştır. Okuyuşlar için kullanılan kısaltmalar şunlardır:

[T] Tryjarski 1965: 423-428.

[K] Karjaubay 1980: 90-93.

[KT] Klyaştornıy-Tryjarski 1990: 65-68.

[Ö] Barutçu Özönder 2000: 126-131.

[Ba] Bazilhan 2005: 128.

[KB] Kormuşin-Battulga 2013: 204-219.

[A] Aydin 2018: 90-91.

[B] Battulga 2020: 142.

(1)





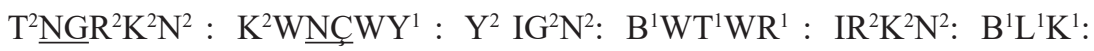

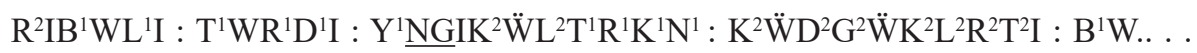
$\mathrm{IK}^{2} \mathrm{IN}^{2}: \mathrm{K}^{1} \mathrm{Y}^{1} \mathrm{~A}: \mathrm{T}^{2} \mathrm{G}^{2} \mathrm{~B}^{2} \mathrm{~K}^{2} \mathrm{~B}^{1} \mathrm{WL}^{1} \mathrm{ZWN}^{1}$

\section{Yazı çevirimi}

[T] /.../ kunçuy/.../butun iş /.../ u[o]k kül tarkan /.../

[K] tenir ekin kunçuy yüzi batur iç ... örkim ... ka ... yılka bütkedük ... ay yana Kül-Tarkan küdegü agız erti but anta kaya etin bek bolzun

[KT] teyriken kunçuy: yigen butur [botor? botur? butor?] irkin yasal [yasaul? yaşil?] kazgan turdi: kani kül [köl?] tarkan : keldak öküz [öguz?] erti bu nça [...] ikin kaya tegdik bolzun

[Ö] t(e)ฤr(i)k(e)n : kunç(u)y : yig(e)n : botur irk(i)n ... yılka büt(ü)kd(ü)k : 1dur (a)nç(a) y(a)y(1)ya köl t(a)rk(a)n : küd(e)gü (a)g(a)z (e)rti : bo (a)t (a)nta : k(a)yat(e) $\mathrm{n}$ b(e)k bolzun

[Ba] teyriken kunçuy Jegen butur Erkin Eki yılkı kün .1tug dar yayı Kül tarkan kü edgü er erikten bu1...n: kaya ak edgü bolzun 
[KB] tẹriken kunçuy : yigen botur irkin : balık eri : bolı turdı : yạı kül tarkan : küdegü kelürti : buna bügikin kaya teg bek bolzun

[A] tẹr $<\mathrm{i}>$ ken kunçuy yėgen botur èrkin awlak? eri bolup turdı yayı köl tarkan küdegü kelirti bunça $<$.. > èki kaya teg bek bolzun

[B] tẹriken kunçuy yigen butur irkin balık eri bolı turdı yại kül tarkan kü edgü kelirti bun teg ikin kaya teg bek bolzun

$\mathrm{t}(\mathrm{e}) \operatorname{pr}(\mathrm{i}) \mathrm{k}(\mathrm{e}) \mathrm{n}: \operatorname{kunc}(\mathrm{u}) \mathrm{y}: \operatorname{yejg}(\mathrm{e}) \mathrm{n}$ : bo tura? : $\operatorname{rrk}(\mathrm{i}) \mathrm{n}: \mathrm{b}(\mathrm{a}) \mathrm{l}(\mathrm{1}) \mathrm{k}$ : (e)ri bolı : turdı : y(a)yı kül t(a)rk(a)n : küd(e)gü k(e)l(i)rti : bo ... èkin k(a)ya : t(e)g b(e)k bolzun

\section{Çeviri}

[T] (je me suis séparé de mes) femmes (princessess), de tous (ou: de mon peuple), de mes compagnons (ou : affaires) ... (moi) Uk (Ok) Kül Tarqan

[K] Небом рожденного принца (священного) лица скрылось (улетело) Высочеству ... к... в году мы (обряды погребения) совер ... Лунного первого месяца зятю Кюль-тархана жертвоприношение принесли. Биркюзой украшали, навек погребли насыпью

[KT] Her Sacred Majesty Princess Yigen, Butur (Botor, Botur, Butor), İrkin, Yasal Qazgan pitched here (their) camp. Her (?) father (is) Kül (Köl) Tarqan. We arrived. There was a river. We penetrated (so far) as (these) two rocks. Let it be (known).

[Ö] Tengriken Prensesi Yigen Botur İrkin (maiyetinde) ... yılında hazırladık. (Onlar) götürürler. Böylece, (bu yılın) yazında Köl Tarkan Küdegü “Güveyi” (sanıyla) saadetli/bahtiyar/devletli idi. Bu san onda kayadan (daha) dayanıklı/berk olsun.

[Ba] Тоңірікен ханшайым : Йеген Бүтүр Еркін екі жылға күн ? жаңа Күл тархан атағы игі ер ерікті ... жартас ақ игі болсын.

[KB] Племянник супруги Божественного - Ботур - иркин жил в горо де в качестве его дружинника. Вновь (назначенный ) Кюль-тархан привел (его сюда) в качестве (своего) зятя. В связи с этим пусть будет крепкое как скала здравие им обоим!

[A] Kutlu prenses, Yegen Botur Erkin Avlak eri olmuştu? Yangı Köl Tarkan güvey getirdi. Bunca $<\ldots>$ orduyu $<\ldots>$ iki kaya gibi sağlam olsun!

[B] Passed away princess('s) cousin Butur Irkin became soldier of the city, and dwelled. New Köl Tarkan send a good news. Let it set as root. Wish you be strong as rock. 
Kutsal Prenses yeğen(i) bo Tura? Ėrkin şehr(in) asker(i) olunca/olup?, durdu? Yạı Kül Tarkan güvey getirdi. Bu... ikisi kaya gibi sağlam olsun!

\section{Satır Açıklamalar:}



Sözcük Ongi 5/6/8, Karabalgasun I/1, TÇ 6/1, Hangiday/4, Hutag Uul/1 ve Erdal tarafindan yayımlanan 'Adrianov Koleksiyonundan Bilinmeyen Bir Yenisey Yazıtı'nda 2/4 karşılaşılmıştır.

Clauson sözcüğe 'dindar' anlamını verirken (1972: 525a), Ongi yazıtında, özellikle Uygur metinlerinde, özel addan ziyade niteleyici bir unvan olduğunu söyler (Clauson, 1957: 185). DLT’de “keşiş, bilgin” açıklaması yer alır. Sözcüğün teyri+ken biçiminde oluştuğu düşünülmektedir (Tekin, 2016: 81).

T kunçuy sözcüğünden önce $\mathrm{y} . \mathrm{m}[?] \mathrm{N}^{2}$ harflerini tespit etmiş ancak herhangi bir okuma yapmamıştır.

$\mathrm{K}$ tarafından teyir ekin okunmuş, takip eden yayınların tamamı teyriken olarak devam etmiştir.

KT teyriken'in Uygur dönemi metinlerine işaret ettiğini tenriteg biçimiyle de Köktürk dönemi metinlerinde görüldüğ̈nü belirtir ve 'her Sacred Majesty' olarak anlamlandirır (1990: 67).

B merhum (passed away); КВ ‘Божественного»; A 'kutlu'; bu çalışmada ise 'kutsal' anlamı verilmiştir.

D $\gg>$ N kunçuy

KT D 20, BK D 16, TÇ 3/1,2 ve Yenisey Yazıtlarında sıkça geçmektedir.

Çince 公主 gong zhu “imparatorun kızı, prenses” sözcüğünden gelir (DTS: 466; Ölmez, 1999: 59, Li, 2019: 356).

Clauson kunçuy sözcüğünün ilk zamanlarda Çin İmparatorluğu'nun kağanlara gelin olarak gönderdiği kızları için kullanılırken daha sonra devlet yönetiminden bağımsız eş için kullanılmaya başlandığını belirtir (1972: 635a).

DLT'de ise 'hatundan bir derece aşağıda bulunan kadın' olarak geçer (2019: 302). Moğolistan bölgesi yazıtlarında 'prenses' anlamılla (KT D 20, BK D 16 vb.) Yenisey yazıtlarında (E/27, E/25, E/65 vb.) umumiyetle eş anlamında kullanılmıştır (Kormuşin 2017: 331). 
Arhanan yazıtında KB ‘супруги’ diğer okuyuşlarda ise 'prenses' olarak alınmıştır.

D $>\downarrow$ yazımı Köktürk dönemi yazıtlarında (KT D 20, K 9; BK D 17, G3) karş1mıza çıkarken TÇ 3/1 ve Yenisey yazıtlarında $D\}>N$ olup ' $\downarrow$ ' harfi yerine ' $\boldsymbol{N}$ ' ile yazılış dikkat çekmektedir. Arhanan yazıtındaki kunçuy yazımı Tayhar Çuluu ve Yenisey Yazıtlarının diliyle örtüşür.

Ner9 yegen

MÇ B 8; Sü 8; TÇ 7/3; KÇ 21/26; KT D 33; Ç 2; E 5/2, 8/3, 59/1 yazıtlarında geçmektedir.

Clauson 'küçük kız kardeşin oğlu' olarak alır ve özel adlarda da görüldüğünü belirtir (1972: 912b-913a; DTS: 252). Akrabalık adı olarak ayrıntılı bilgi için bkz. (Li 2019: 276). "yeğen" anlamı MÇ B 8, Sü 8 yazıtlarında, diğer yazıtlarda (TÇ 7/3, KÇ 21, KT D 33, E 59/1 E 5/2 8/3) ise özel adın parçası olarak karşımıza çıkar.

Sözcük bu yazıtta KT, Ö, Ba ve A tarafindan özel ada dahil edilirken KB, B ve bu çalışmada 'yeğen' anlamı verilmiştir.

4> $5>$ J bo tura?

tura temel olarak 'arkasına sığınacak bir şey' anlamında hem kalıcı tahkimatlar hem de geçici olarak yere sabitlenebilen ve hareket ettirilebilen taşınabilir 'göğüs siperi' için kullanılır (Clauson 1972: 531a). DLT'de tora şeklinde “sı̆̆ır derisinden yapılan kalkan; düşmandan korunmak için kullanılan her şey” olarak açıklanır (2019: 484). DTS'de ise tura I sağlamlaştırılmış konut; kale (587).

Yazıtta KT'nin çalışmasından itibaren araştırmacılar tarafından botur/botor/ butur şekillerinde okunan sözcük özel ad olarak alınmıştır. Ancak daha önce karşılaşılmış bir sözcük değildir. Ö, A ve B sözcükle ilgili herhangi bir açıklamada bulunmaz. KT sözcügü DLT ve Clauson'da geçen buturğak 'giysilere takılan bir çeşit diken; çökmekten kurtarmak için ikiye bölünmüş ve etrafına sarılmış bir ağaç’ ile ilişkilendirir (1990 :67). KB ise yazıtın kahramanının adı olduğu için iki ünlüsünün de yazıldığııı belirtir ( 2013: 215).

Sondaki $\checkmark$ harfinin hakkâkın ihmaliyle yazılmadığı düşünüldüğü takdirde sözcüğü bilinen bir sözcük olan tura olarak okumak mümkündür. 
NYYT erkin

BK G 14, KT D 34, KÇ D 21, Tar K 6, TÇ 7/3, 8/2, Ç 2 yazıtlarında geçer.

Clauson irkin şeklinde alıp “kabile liderinin ailesinden gelen kağan’ın altında beg'in üstünde olan bir unvan” olarak açıklar (1972: 225a). Tekin ise yüksek rütbeli bir unvan olarak alır (1983: 836).

Arhanan yazıtında i'li biçimde 'Nץ$\uparrow r '$ yazılırken Tar K 6, TÇ 7/3, 8/2 yazıtlarında ' $N$ 'Ү' olarak i'siz yazılmıştır. Yazılıştaki bu ikiliğin kapalı èyi işaret ettiği söylenebilir (Thomsen, 1896: 15-16).

Yazıtta érkin sözcügü KT tarafından tespit edilmiştir.

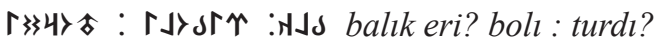

$\mathrm{K}, \mathrm{KT}$, Ö ve Ba tarafindan bu kısım için tespit edilen harfler ve okuyuşlar oldukça farklıdır. Yazıtı yerinde gören Ts. Battulga harfleri $\mathrm{B}^{1} \mathrm{~L}^{1} \mathrm{~K}^{1}$ : $\mathrm{R}^{2} \mathrm{IB}^{1} \mathrm{WL}{ }^{1} \mathrm{I}$ : $\mathrm{T}^{1} \mathrm{WR}^{1} \mathrm{D}^{1} \mathrm{I}$ olarak vermiştir (2005: 117).

bol- eyleminin zarf-fiil eki olarak $-I$ almış olması dikkat çekicidir. E 45/3 yazıtında $-(X) p$ almış haliyle karşılaşırız ancak Kormuşin ' $\mathrm{P}$ ' olarak okuduğu bu harfin 1 'P' değil r 'I' şeklinde yazılmış olduğunu bu durumun hakkakın 'aynalı görme' hatasından kaynaklandığını bildirerek ‘bolup’ okur (2017: 241). Benzer durum E 10/8 yazıtında da vardır (Kormuşin, 2017: 261).

Arhanan Yazıtında KB ve B ‘bolı’, A ise ‘bolup’ olarak aktarmıştır. Bu çalışmada da bolı okuyuşu izlenmiştir.

tur- 'durmak; ayağa kalkmak; hareketsiz durmak' (Clauson, 1972: 329b).

Tar K 2 yazıtında tur - $d I$ ekli biçimiyle karşımıza çıkar.

Yazıtta KT “pitched camp”. 'kamp kurmak' KB, B ‘yerleşmek; ikamet etmek' A bolup turdl 'olmuştu' olarak anlamlandırmıştır.

TYD yayı

yayı anlamı 'yeni' olmakla birlikte bir şeyin (yılın gibi) parçası olma durumu için kullanılır, Eski Uygurcada ayın ilk on gününü ifade eder (Clauson, 1972: 943b).

Sözcük takvim sisteminde 8. yüzyılın ilk yarısından itibaren görülür. Bu kullanım kalıbıyla Uygurcanın söz varlığına aittir (Ölmez 2018: 139).

Yazıtlarda ayın ilk on gününü işaret etmesi anlamıyla her zaman $+k a$ eki almıştır (MÇ K 9, D 1/3/5/6 B 1/2/4; Chang'an yazıtı/17). Eksiz biçimiyle yalnızca bu yazıtta, Arhanan'da, karşımıza çıkmaktadır. 


\section{YнY kül}

Tes G 1; MÇ K 5, TÇ 6/3, Sevrey 3 yazıtlarında geçer.

Clauson sözcüğün hem özel ad hem de unvan (özellikle ilk dönemlerde) olarak kullanıldığını bildirir. Sözcüğün yazımının - $-\ddot{u}$ - mü -ö- mü olması gerektiği konusunda Çince karakterlerin aktarımının (transkripsiyonunun) $k$ 'üe olması - ̈̈- yazımını destekler (1972: 715a).

II. Köktürk kağanı Kül Tégin adında geçmesi sebebiyle $\ddot{o}$ mü $u ̈$ mü okunması gerektiği çokça tartışılmıştır. İlk okumalarda kül tercih edilmiştir. Sonrasında Moğolca Dalay Lama unvanındaki Dalay 'deniz, umman' ile göl sözcügü karşılaştırılmış köl yaygınlık kazanmıştır (Ölmez, 2011: 632). Konuyla ilgili temel görüşler şöyledir:

1. Bazin ayrıntılı olarak okuyuşları değerlendirip, DLT'de geçen köl bilge han 'göl gibi akıl dolu' anlamından yola çıkarak köl okuyuşunu tercih eder (Bazin, 1981:1-7).

2. Temir ise kül okuyuşunu 'ateş kültü' ve Moğolca otçigin 'ateş prens' ile ilişkilendirir (1981: 194-200).

Ö, A, B köl ; T, K, Ba, KB kül okumuştur. Bu çalışmada kül okuyuşunu takip ediyoruz.

\section{วกน}

BK G 13/14, KÇ 1, Tar B 6/8 K 2/3/5/6, TÇ 6/3, Sü 3 yazıtlarında karş1mıza çıkar. Clauson tarxan şeklinde alır ve eski yüksek bir unvan olduğunu söyler. Pulleyblank'in Xiongnuların kağanlarının yüksek bir uvanı olan shan-yü (Eski Çince *dān-gwag) ile tarkan sözcüğünü karşılaştırmasının en iyi etimoloji olarak değerlendirir. Ayrıca sözcüğün çoğul $(+t)$ şeklinin (tegin=tegit gibi) tarxa(n)t olması gerektiğini bildirir (Clauson, 1972: 539b).

\section{NexNY küdegü}

Yenisey E 3/6 yazıtında geçer.

*küde- "evlenmek" fiilinden -gü ekiyle , "k1zın kocas1, damat, evlenmekte olan erkek" anlamlarına gelir (Clauson, 1972: 703a; Li, 2019: 412).

B ve Ba kü edgü "iyi haber" şeklinde; $\mathrm{K}, \mathrm{O}, \mathrm{KB}, \mathrm{A}$ ve bu çalışmada küdegü "güvey" olarak alınmıştır.

「hҮYץ kelir-/kelür-

“getirmek” fiili Orhon Yazıtlarında (KT G 11, K 1; T53 vb.) $\mathrm{K}^{2} \mathrm{~L}^{2}$ ẄR şek- 
linde yazılmıştır. MÇ D3'te $\mathrm{K}^{2} \mathrm{~L}^{2} \mathrm{R}^{2} \mathrm{~T}^{2} \mathrm{IM}$; MÇ G 3 satırında ise $\mathrm{K}^{2} \mathrm{~L}^{2} \mathrm{IR}^{2} \mathrm{~T}^{2} \mathrm{I}$ şeklinde karşımıza çıkar. Yenisey Yazıtlarından E 28/1'de $\mathrm{K}^{2} \mathrm{~L}^{2} \mathrm{R}^{2} \mathrm{~T}^{2} \mathrm{I}$ şeklinde “doğurmak” anlamılla geçmektedir.

Tekin ve Erdal tarafından kel- fiiline gelen -(X)r- eki ettirgen çatı eki olarak alınmıştır (Tekin, 2009: 93; Erdal 1991: 709). Ayrıca Erdal kel- fiilinin ettirgen şeklinin zarfiil ve geniş zaman halinde $i$ barındırmasıyla ilişkili olduğunu, asıl şeklin *keli- olabileceğini kelür-şeklinin ise ikincil olabileceğini belirtir (Erdal, 1991: 716).

Arhanan Yazıtında yazımda ne $\ddot{u}$ ne de $i$ yazılmıştır. KB kelürti; A, B kelirti olarak okumuşlardır. Bu çalışmada kelirti okuyuşu takip edilmiştir.

Yर bek

Yazıtlarda bek şekliyle ilk defa burada geçmektedir.

sert; sağlam; sabit olarak anlamlandırılır (Clauson, 1972: 323a; DTS: 92).

DLT'de ise berk sözünün -r- ile genişletilmiş halinin sonradan ortaya çıktığ 1 asıl şeklin bek olduğu bilgisi verilir. Clauson Eski Uygurca metinlerde her iki şeklin de görüldüğünü belirterek buna şüpheyle yaklaşır (1972: 323a; DLT 2019: 106). berk şekliyle Erdal tarafından yayımlanan "Adrianov Koleksiyonundan Bilinmeyen Bir Yenisey Yazıtı”nda karşılaşırız (Erdal, 1998: 88).

(2)

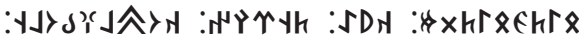

$\mathrm{B}^{2} \mathrm{IT}^{2} \mathrm{G}^{2} \mathrm{~B}^{2} \mathrm{IT}^{2} \mathrm{D}^{2} \mathrm{M}: \mathrm{K}^{1} \mathrm{Y}^{1} \mathrm{~A}: \mathrm{T}^{2} \underline{\underline{\mathrm{NGR}^{2}}} \mathrm{~K}^{2} \mathrm{~N}^{2}: \mathrm{K}^{1} \mathrm{WT}^{1} \mathrm{~L}^{1} \mathrm{G}^{1} \mathrm{~B}^{1} \mathrm{WL}{ }^{1} \underline{\mathrm{NG}}:$

\section{Yazı çevirimi}

[T] b[an] bitig bitdm kayata /.../

[K] ....... bekü bitik bitidim kaya tenir ekin kutlug bolun!

[KT] ben bitig: bitidim kaya: tepriken kutlug bolzun [...] lr

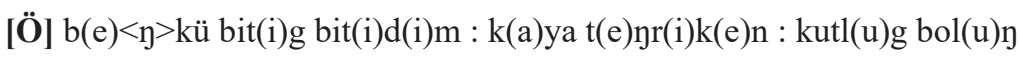

[Ba] b........ bitiçu bitidim: kaya Tejiriken: kutlug bolzun

[KB] bitig bitidim : kaya tenriken : kutlug : bolın

[A] ben bitig bitidim kaya tey $<\mathrm{i}>$ ken kutlug boluy.

[B] bitiç bitidim kaya tẹriken kutlug bolun

...bit(i)g bit(i)d(i)m : k(a)ya : t(e)pr(i)k(e)n : kutl(u)g bol(u)y 


\section{Çeviri}

[T] ... j'écris (cette) inscription sur (dans) le roc

[K] ... Тщательно надпись написал я. Небом рожденный скале. Пусть будет благодатным!

[KT] I wrote the inscription (in) the rock. May Her Sacred Majesty enjoy divine favour(...)

[Ö] Sonsuzluk yazıtı yazdım. İlâhi kaya kutlu olsun!

[Ba] Б.........бітікші жаздым: жартаска Тонірікен: кутты болсын

[KB] Я написал ( эту ) надпись . (Крепкий как) скала Божественный (правитель)- будьте благословенны!

[A] Yazıt yazdım. Kutlu kaya (gibi) kutlu olsun!

[B] I, the writer wrote it. Bless Rocky Heaven.

...yazıt yazdım. Kutsal kaya (gibi), kutlu olun.

\section{Satır Açıklamalar:}

\section{\$ xhrechre bitig biti-}

bitig ve biti- yazıtlarda (KT G 13, BK K 14, MÇ D 8, Tar B 2, Tes G 3 vb.) sıkça geçmektedir.

biti- 'yazmak' (Clauson, 1972: 299a; Tekin, 2016: 85; Ölmez, 2021: 620).

Bu eylemden türetilmiş olan biti-g 'yazıt, yazılı olan her şey' (yazıtlar, kağıda yazılı belgeler) için kullanır (OTWF 184; Ölmez, 2021: 622).

(3)

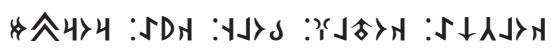

$\mathrm{K}^{2} \mathrm{WL}{ }^{1} \mathrm{C}^{\mathrm{W}} \mathrm{KA}: \mathrm{K}^{1} \mathrm{WT}^{1} \mathrm{~L}^{1} \mathrm{G}^{1}$ : $\mathrm{B}^{1} \mathrm{WL}{ }^{1} \mathrm{NG}$ : $\mathrm{K}^{1} \mathrm{Y}^{1} \mathrm{~A}: \mathrm{R}^{1} \mathrm{WR}^{1} \mathrm{~T}^{1} \mathrm{M}$

\section{Yazı çevirimi}

[T] $/ . . / \mathrm{ku}[\mathrm{o}] 1 / . . . /$ yoluk $/ . . . /$

[K] ........... kulaçkın kutlug bolun! kırın bedizdim

[KT] ir[k]a ina y s 1 [yasaul? yaşil? ]: [...] kutlug bolzun kirurtim

[Ö] (a)y(a)ru kolçuk(u)y : kutl(u)g bol(u)y : $\operatorname{kır}(1) n$ : b(e)dz(e)d(i)m

[Ba] k... kulçuk.. kutlug er ara bolzun bedizdim

[KB] kul çoka ( açuka-?) : kutlug : bolın : kayaru : urtım

[A] kul açuk a kutlug bolun kaya $<\mathrm{u}>\mathrm{r}<\mathrm{t}>$ urtum

[B] kul açuka (açoka) kutlug bolun kaya ururtum

kulçuk-a: kutl(u)g : bol(u)n : k(a)ya : ru urt(u)m 


\section{Çeviri}

[T] ..... esclave (ou: bras) ... sacrifice..

[K] .... твоя сажень ((тело)) пусть будет благодатным! Вырезал, начертил я.

[KT] May İrkin (?) Yasal (? ...) enjoy divine favour.

[Ö] Onlara (kut) ihsan edin! Kutlu olun. Yalçın dik kayayı bezedim/süsledim

[Ва] К.... кутты ер арасы болсын бодіздедім

[KB] Кул - Чока / Ачука ( Раб Божий Чока / Ачука ) - будьте

благословенны ! Я выбил ( все это ) на скале.

[A] (Adım) Kul Açuk. Kutlu olun. Kaya(ya) yazı vurdurdum.

[B] Bless servant Açoqa. Engraved on the rock by me.

(Ben) Hizmetkâr. Kutlu olun. Kayaya yazı yazdım.

\section{Satır Açıklamalar:}



kul BK D 7/17/18; KT D 7/20/21/24; MÇ G 9, D 1; Gurbelçin Yazıtı, E 69/2 vb. yazıtlarda geçer.

kün 'kadın köle, cariye' sözcüğünün eril karşıllı̆ı kul 'köle, erkek köle' anlamindadir (Clauson, 1972: 615a; DTS: 464).

kulçuk kul sözcüğünün $+c ̧ U k$ küçültme eki alarak oluşturulmuş şekli gibi durmaktadır. kapçuk 'küçük kap', küpçük 'küçük kap', otçuk 'küçük bir ateş yeri' sözcüklerinde olduğu gibi (OTWF: 107-108). Sondaki $a$ ise Yenisey Yazıtlarında sıklıkla rastladığımız ünlem sesi olarak alınmıştır.

Sözcüğü Ö kolçukuך şeklinde okur ve qol- 'istemek' eylemine dayandırır (2000: 130). Ba kulçuk; KB kul çoka/açuka; A kul açuk; B açoka/açoka olarak okumuşlardır. Bu çalışmada kulçuk-a 'hizmetkâr, köle' okuyuşu tercih edilmiştir.

\section{\$令4〉 : SDN kaya:ru urtum}

Yazıtlarda genel olarak iki nokta sözcükleri birbirinden ayımak için kullanılmıştır. Ancak bazı Yenisey Yazıtlarında (E 1/1-2, E 22/1 gibi) eklerin de kimi zaman iki nokta ile ayrıldığı görülür.

kaya:ru 'kayaya' sözcüğünde de aynı durum söz konusudur. Sözcük kaya+rU yön gösterme ekinden (Tekin 2016: 125; Erdal 2004: 178) oluşmaktadır.

KB kayaru : urtım; A kaya $<u>r<t>$ urtum; B kaya ururtum; bu çalışmada ise kaya:ru urtum 'kayaya yazdım' şeklinde ele alınmıştır. 


\section{Sonuç}

Arhanan Yazıtı üç satırlık kısa bir yazıt olmasına rağmen üzerine birçok araştırmacı çalışmıştır. İlk çalışmalar rötuşlu fotoğraflara ve el kopyalarına dayanmaktadır. Bu durum harf tespitini zorlaştırmış ve okuma farklılıklarını ortaya çıkarmıştır. Bu çalışmada Arhanan Yazıtı üzerine yapılan çalışmalara yer verilerek bütüncül bir bakış açısı sağlanmaya çalışılmıştır. Birinci satırda yer alan daha önce botur/butur/botor şekillerinde okunan özel adın tura olarak okunması ve ikinci satırda geçen boluך sözcüğü “olun” şeklinde anlamlandırılması önerilerinin yanında sözcüklerle ilgili notlara yer verilmiştir. Makalede yer alan notlar çerçevesinde ortaya konulan yazıt metni şöyledir:

\section{Yazı çevirimi}

(1) t(e)pr(i)k(e)n : kunç(u)y : yėg(e)n : tura? : $\operatorname{erk}(i) n: b(a) l(1) k$ : (e)ri bolı :

turd1 : y(a)yı kül t(a)rk(a)n : küd(e)gü k(e)l(i)rti : bo ... èkin k(a)ya : t(e)g b(e)k bolzun

(2) ...bit(i)g bit(i)d(i)m : k(a)ya : t(e)nr(i)k(e)n : kutl(u)g bol(u)n

(3) kulçuk-a: kutl(u)g : bol(u)n : k(a)ya :ru urt(u)m

\section{Çeviri}

(1) Kutsal Prenses yeğen(i) Tura Ėrkin şehr(in) asker(i) olunca/olup?, durdu?

Yayı Kül Tarkan güvey getirdi. Bu... ikisi kaya gibi sağlam olsun!

(2) ... yazıt yazdım. Kutsal kaya (gibi), kutlu olun.

(3) (Ben) Hizmetkâr, Kutlu olun. Kayaya yazı yazdım.

\section{Diğer Kısaltmalar:}

BK: Bilge Kağan Yazıtı.

Ç: Çoyr Yazıtı.

MÇ: Moyun Çor Yazıtı.

KÇ: Küli Çor Yazıtı.

KT: Kül Tegin Yazıtı.

Sü: Süci Yazıtı

TÇ: Tayhar Çuluu Yazıtları.

Tar: Taryat yazitı. 


\section{Kaynakça}

Aydın, E. (2018). Uygur Yazıtları. İstanbul: Bilge Kültür Sanat.

Barutçu Özönder, F. S. (2000). Eski Türk Çağı Kaya Yazıtları I.Örük Yazıtı, II. Hangiday Ya zıtı, III. Arhanan Yazıtı. Kök Araştımalar 2/1: 121-133.

Battulga, Ts. (2005). Mongolın Runı Biçgiin Dursgaluud. Corpus Scriptorum, Tomus 1-3.

Ulaanbaatar.

Battulga, Ts. (2020). The Small Monuments of Mongolian Runic Inscription. Archaeological Relicks Of Mongolia Catalogue Series. Ulaanbaatar.

Bazilhan, N. (2005). Kazakstan Tarihı Turalı Turki Derektemeleri II, Köne Türik Bitiktastarı Men Eskertkişteri (Orhon, Yenisey, Talas). Almatı: Dayk.

Bazin, L. (1981). Kül Tegin ou Köl Tegin? Scholia: K. Röhborn- H. W. Brands (hrsg.): Scholia. Beiträge zur Turcologie und Zentralasienkunde. (Annemarie von Gabain zum 80.Geburtstag am 4. Juli 1981 dargebracth von Kollagen, Freunden und Schülern). Wiesbaden, 1981: Harrasowitz. 1-7.

Clauson, Sir G. (1957). The Ongin Inscription. Journal of the Royal Asiatic Society of Great Britain and Ireland. No. 3/4 s. 177-192.

Clauson, Sir G. (1972). An Etymological Dictionary of Pre-Thirteenth-Century Turkish. Oxford: Oxford at the Clarendon Press.

Erdal, M. (1991). A Grammer of Old Turkic. Leiden: Brill.

Erdal, M. (1991). Old Turkic Word Formation. A Functional Approach to the Lexicon, I-II, Wiesbaden: Otto Harrasowitz (OTWF).

Erdal, M. (1998). Eine unbekannte Jenissei-Inschrift aus der Adrianov-Kollektion, J. P. LautMehmet Ölmez (hzl.): Bahşı Ögdisi. (Festschrift für Klaus Röhrborn anlässlich seines 60. Geburtstag/60. Doğum Yı1ı Dolayısıyla Klaus Röhrborn Armağanı) Simurg. Freiburg-İstanbul, 83-96.

Kaçalin, M. S. (2019). Dîvânu Lugâti-t-Türk. Mahmûd el-Kâşgarî. (Yay. Haz. Mehmet Ölmez). İstanbul: Kabalcı Yayıncılık.

Karjaubay, S. (1980). Nadpis'na skale Arxanana. Xel Zoxiolın Sudlal, UB., Tom. XIV, Fasc. $15,90-93$.

Klyaştornı, S. G. ve Tryjarski, E. (1990). An imroved edition of the Arkhanen ins cription. Rocznik Orientalistyczny. 47/ 1: 65-68.

Kormuşin, İ. V. ve Battulga, Ts. (2013). Тюркологический Сборнок (2011-2012), Российская академия наук Институт восточных рукописе, Москова, 204-219.

Kormuşin, İ. V. (2017). Yenisey Eski Türk Mezar Yazıtları Metinler ve İncelemeler, 
Çev. Rysbek Alimov. Ankara, Türk Dil Kurumu Yayınları.

Li, Y.-S. (2017). Türk Dillerinde Akrabalık Adları. Türk Dil Kurumu Yayınları. Ankara.

Nadelyayev, V. M., Nasilov, D. M., Tenişev, E. R., Şçerbak A. M. (1969). Drevnetyurkskiy slovar'. Leningrad: Nauka.

Ölmez, M. (1999). Eski Türk Yazıtlarında Yabancı Öğeler (3), Türk Dilleri Araştırmaları, S. 9, s. 59-65.

Ölmez, M. (2011). Eski Uygur ve Çin Kaynakları Işı̆̆ında Orhon Yazıtlarında Geçen Yer ve Kişi Adları. Orhon Yazıtlarının Bulunuşundan 120 Yıl Sonra Türklük Bilimi ve 21. Yüzyıl Konulu III. Uluslararası Türkiyat Araştırmaları Sempozyumu. 26-29 Mayıs 2010, Bildiriler Kitabı, ed. Ülkü Ç. Şavk, 2. cilt, Ankara 629-640.

Ölmez, M. (2018). Uygur Hanlı̆̆l Yazıtları. Ankara: Bilgesu Yayıncılık.

Ölmez, M. (2021). Eski Türkçedeki biti-, bitig ve bitigüçi Sözleri Hakkında. T. Karaayak-U. Uzunkaya (hzl.): Esengü Bitig. (Doğumunun 60. Yılında Zühal Ölmez Armağanı). Kesit Yay. İstanbul, s. 619-629.

Rintchen, E. B. (1968). Les designs pictographiques et les inscriptions sur les rochers et sur les stelles en Mongolie recueillis (Corpus Scriptorum Mongolorum). Ulaanbaatar.

Tekin, T. (1983). Kuzey Moğolistan'da Bir Uygur Anıtı: Taryat (Terhin) Kitabesi. Belleten 46/184: 795-838.

Tekin, T. (2016). Orhon Türkçesi Grameri. Türk Dil Kurumu Yayınları. Ankara.

Temir, A. (1981). Türkçe Kül-Tigin ve Moğolca Otçigin Adları Üzerine, K. Röhborn- H. W. Brands (hrsg.): Scholia. Beiträge zur Turcologie und Zentralasienkunde.(Annemarie von Gabain zum 80.Geburtstag am 4. Juli 1981 dargebracth von Kollagen, Freunden und Schülern). Wiesbaden, 1981: Harrasowitz. s. 194-200.

Thomsen, V. (1896). Inscriptions de l'Orkhon déchiffrées. (Mémoires de la Société Finno-Ougrienne 5, 1-224). (Orhon ve Yenisey Yazıtlarının Çözümü IIlk Bildiri, Çözülmüş Orhon Yazıtları. Çev. Vedat Köken, Ankara, 1993: TDK, 13-240).

Tryjaski, E. (1965). L'inscription turque runiforme d' Arkhanen en Mongolie. Ural-Altaische Jahrbücher. 36/3-4: 423-428. 